Çukurova Üniversitesi Mühendislik Mimarlık Fakültesi Dergisi, 31(2), ss. 59-66, Aralık 2016

Çukurova University Journal of the Faculty of Engineering and Architecture, 31(2), pp. 59-66, December 2016

\title{
Kare Temeller Altında Gerilme ve Taşıma Gücü Analizi Yakup TÜREDi் ${ }^{* 1}$, Murat ÖRNEK ${ }^{1}$
}

\author{
${ }^{1} \dot{I s k e n d e r u n ~ T e k n i k ~ U ̈ n i v e r s i t e s i, ~ M u ̈ h e n d i s l i k ~ v e ~ D o g ̆ a ~ B i l i m l e r i ~ F a k u ̈ l t e s i, ~ I n s ̧ a a t ~ M u ̈ h e n d i s l i g ̆ i ~}$ \\ Bölümü, İskenderun, Hatay
}

Geliş tarihi: 01.06.2016

Kabul tarihi: 23.11 .2016

$\ddot{\mathbf{O z}}$

Bu çalışmada, gevşek kum zemine oturan 4 farklı model kare temel altında meydana gelen düşey gerilme artışları ve taşıma gücü değişimleri deneysel ve teorik olarak araştırılmıştır. İlave düşey gerilme artışları 4 farklı derinlikte $(12,5 \mathrm{~cm}, 25 \mathrm{~cm}, 37,5 \mathrm{~cm}$ ve $50 \mathrm{~cm})$ yerleştirilen gerilme ölçer ile ölçülmüştür. Deney sonuçları, Newmark yöntemi ile karşılaştırılmıştır. Ayrıca yük-oturma değerleri ise yük hücresi ve deplasman ölçerler vasıtasıyla elde edilmiştir. Deneyler, İskenderun Teknik Üniversitesi İnşaat Mühendisliği Bölümü Geoteknik Laboratuvarı'nda yapılmıştır. Sonuçlar incelendiğinde, deneysel ve teorik sonuçlar arasında bir uyum olduğu gözlenmiştir. Ayrıca temel oturum alanı arttıkça taşıma gücü değerleri de artmıştır.

Anahtar Kelimeler: İlave düşey gerilme, Taşıma kapasitesi, Kare temel, Gevşek kum

\section{Stress and Bearing Capacity Analyses under Square Footings}

\begin{abstract}
In this study, the vertical stress and the bearing capacity values occurred under four different sized model square footing rested on the loose sand were investigated experimentally and theoretically. The vertical stresses were measured with transducer placed at the four different depths $(12.5 \mathrm{~cm}, 25 \mathrm{~cm}, 37.5 \mathrm{~cm}$ ve 50 $\mathrm{cm})$. The test results were compared with theoretical Newmark Method results. And also the loadsettlement curves were obtained with load cell and displacement transducer. The model tests were conducted in the Geotechnical Laboratory of Civil Engineering Department of Iskenderun Technical University. It is showed that the model test results are compatible with the theoretical results. Also the bearing capacity increases with increase in the footing area.
\end{abstract}

Keywords: Vertical stress, Bearing capacity, Square footing, Loose sand

\footnotetext{
*Sorumlu yazar (Corresponding author): Yakup TÜREDİ, yakup.turedi@iste.edu.tr
} 


\section{GíRiş}

Gerek zemin tabakalarının kendi ağırlıklarından gerekse de uygulanan dış yükler altında zemin içinde gerilmeler oluşmaktadır. Gerilmeler uygulanan yükün şiddetine ve yükün uygulandığı alanın boyutlarına bağlı olarak değiştiğinden, gerilme dağılımının bilinmesi, birçok problemin çözümü ve projelerin tasarımında oldukça önemlidir.

Zeminler, homojen ve izotrop olmayan malzemelerdir. Zeminlerin çok karmaşık bir yapıları olması; özellikle çevre koşullarına, jeolojik tarihçesine ve zamana bağlı olarak büyük değişiklikler gösterdiğinden, zemin içerisinde gerçekçi gerilme-deformasyon analizleri yapmak oldukça zordur. $\mathrm{Bu}$ nedenle Elastisite Teorisi kullanılırken şu kabuller yapılmaktadır. i) Zemin elastik olup, gerilme-deformasyon ilişkisi doğrusaldır. ii) Zemin ortamı homojendir. iii) Zemin ortamı izotroptur ve yarı sonsuzdur [1].

Keskin ve arkadaşları [2] tarafından kum zemin üzerine oturan kare temellerden oluşan ilave düşey gerilmeler deneysel ve sayısal olarak incelenmiş ve sonuçlar literatürde yer alan Boussinesq yöntemi ile karşılaştırılmıştır. Sonuç olarak, belirli derinlik seviyelerinde deneysel, sayısal ve teorik sonuçlar arasında genel bir uyum gözlenmiş ve derinlik arttıkça ölçülen gerilme değerlerinin azaldığ gözlenmiştir.

Bağrıaçık ve Laman [3] tarafından, donatısız ve geogrid donatılı kum zeminler üzerine oturan yüzeysel temellerden dolayı zeminde meydana gelen ilave düşey gerilme davranışları araştırılmıştır. Sonuç olarak; farklı geometrilerdeki temellerde şekil etkisinin önemli mertebelerde olduğu görülmüştür. Elde edilen bulgular sonucunda, geogrid donatılı kum zemin olması durumunda yüzeysel temellerden dolayı zemin içinde oluşan ilave düşey gerilmelerin, donatısız duruma göre, yaklaşık \%27 oranında azaldığı görülmüştür.

Yodsa-nga ve arkadaşları [4] tarafindan lös zemine oturan radye temeller altında oluşan gerilme dağılışları arazi deneyi ve sayısal model ile araştırılmıştır. Ayrıca, gerilme değerleri üç farklı sayısal analiz yöntemi ile tahmin edilmiştir. Sonuç olarak, sayısal yöntemlerin daha gerçekçi sonuçlar ortaya koyduğu görülmüştür.

Literatürde farklı zemin ve temel türünde meydana gelen ilave düşey gerilmelerin tahmini ve tespiti, deney düzenekleri ve teknikleri ile ilgili birçok çalışma bulunmaktadır [5-18].

Boussinesq [12] ifadesi L uzunluğunda ve B genişliğindeki q üniform yükü ile yüklenmiş dikdörtgen bir alanın altında oluşan gerilmelerin belirlenmesinde kullanılabilmektedir. Dikdörtgen alanın bir köşesi altında ve $\mathrm{z}$ derinliğindeki bir noktada oluşan ilave düşey gerilme $\Delta \sigma_{z}$ Şekil 1'de verilmiştir.

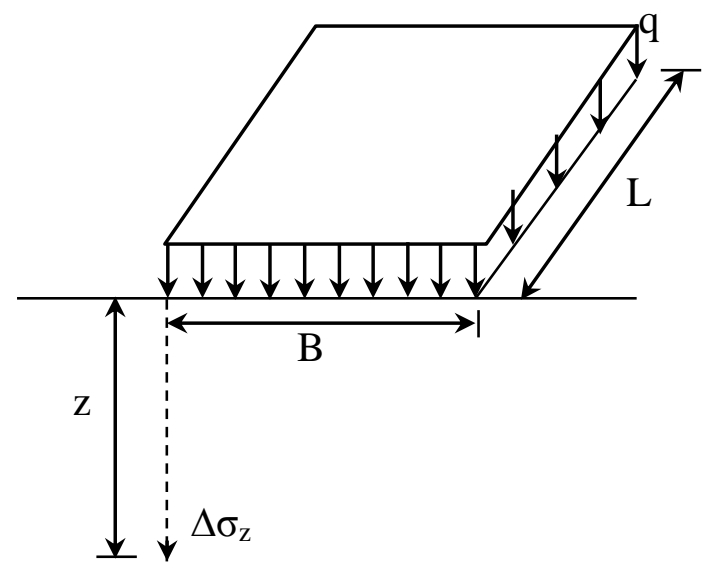

Şekil 1. Üniform yüklü dikdörtgen alanın bir köşesi altında gerilme artışı

İlave düşey gerilme, Newmark [19] tarafindan Boussinesq [11]'in tekil yük ifadesinin integrasyonu ile,

$\Delta \sigma_{z}=q I_{r}$

Burada $I_{r}$ etki faktörü ise aşağıdaki gibi yazılabilmektedir. 
$I_{r}=\frac{1}{4 \pi}\left[\frac{2 m n \sqrt{m^{2}+n^{2}+1}}{m^{2}+n^{2}-m^{2} n^{2}+1}\left(\frac{m^{2}+n^{2}+2}{m^{2}+n^{2}+1}\right)\right]$

$+\tan ^{-1} \frac{2 m n \sqrt{m^{2}+n^{2}+1}}{m^{2}+n^{2}-m^{2} n^{2}+1}$

ifadede $m=B / z$ ve $n=L / z^{\prime}$ dir

Bu çalışmada, gevşek kum zemine oturan 4 farklı kare $30 \mathrm{~cm} \times 30 \mathrm{~cm}(6 \mathrm{~B} \times 6 \mathrm{~B}), 25 \mathrm{~cm} \times 25 \mathrm{~cm}$ (5B x 5B), $20 \mathrm{~cm} \times 20 \mathrm{~cm}(4 \mathrm{~B} \times 4 \mathrm{~B})$ ve $15 \mathrm{~cm} \mathrm{x}$ $15 \mathrm{~cm}(3 \mathrm{~B} \times 3 \mathrm{~B})$ model temel altında meydana gelen ilave düşey gerilme ve taşıma gücü davranışları deneysel ve teorik olarak araştırılmıştır. İlave düşey gerilme artışları 4 farklı derinlikte $(2,5 \mathrm{~B}, 5,0 \mathrm{~B}, 7,5 \mathrm{~B}$ ve $10,0 \mathrm{~B})$ ve her bir derinlik için yatayda temelin merkezi $0,0 \mathrm{~B}, 3,0 \mathrm{~B}$ ve $6,0 \mathrm{~B}$ konumlarında gerilme değerleri elde edilmiştir. Ayrıca yük-oturma değerleri de elde edilmiştir. Elde edilen sonuçlar, literatürde mevcut teorik yöntemlerle karşılaştırılmıştır. Bu çalışmada toplam 16 adet model deney yapılmıştır.

\section{MATERYAL VE METOD}

Model deneyler, İskenderun Teknik Üniversitesi, İnşaat Fakültesi, İnşaat Mühendisliği Bölümü, Geoteknik Laboratuvarı'nda yapılmıştır.

\subsection{Model Temeller}

Deneylerde kullanılan kare temellere ait ölçüler Çizelge 1'de verilmiştir. Şematik olarak Şekil 2'de verilmiştir [17]. Genişlik $5 \mathrm{~cm}$ için B cinsinden ifade edilerek temeller bu şekilde kategorize edilmiştir (Çizelge 1).

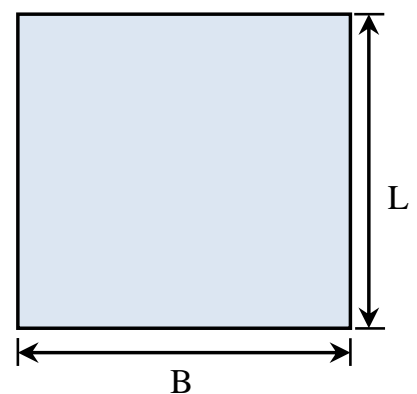

Şekil 2. Model temel
Cizelge 1. Model temellerin boyutları

\begin{tabular}{|c|c|c|c|}
\hline $\mathbf{K}_{\mathbf{1}}(\mathbf{6 B})$ & $\left.\mathbf{K}_{\mathbf{2}} \mathbf{( 5 B}\right)$ & $\left.\mathbf{K}_{\mathbf{3}} \mathbf{( 4 B}\right)$ & $\left.\mathbf{K}_{\mathbf{4}} \mathbf{( 3 B}\right)$ \\
\hline $\mathrm{BxL}\left(\mathrm{cm}^{2}\right)$ & $\mathrm{BxL}\left(\mathrm{cm}^{2}\right)$ & $\mathrm{BxL}\left(\mathrm{cm}^{2}\right)$ & $\mathrm{BxL}\left(\mathrm{cm}^{2}\right)$ \\
\hline $30 \times 30$ & $25 \times 25$ & $20 \times 20$ & $15 \times 15$ \\
\hline
\end{tabular}

\subsection{Deney Kasası ve Düzeneği}

Model deneyler, ebatları $125 \mathrm{~cm}$ x $100 \mathrm{~cm}$ x 100 $\mathrm{cm}$ (uzunluk, genişlik, derinlik) olan dikdörtgen kesitli bir kasa içerisinde gerçekleştirilmiştir (Şekil 3). Deney kasası iskeleti çelik profillerden olup, ön ve arka yüzü $10 \mathrm{~mm}$ kalınlığında cam, yan yüzeyler ile alt taban ise $3 \mathrm{~mm}$ kalınlığındaki metal malzemeden imal edilmiştir.

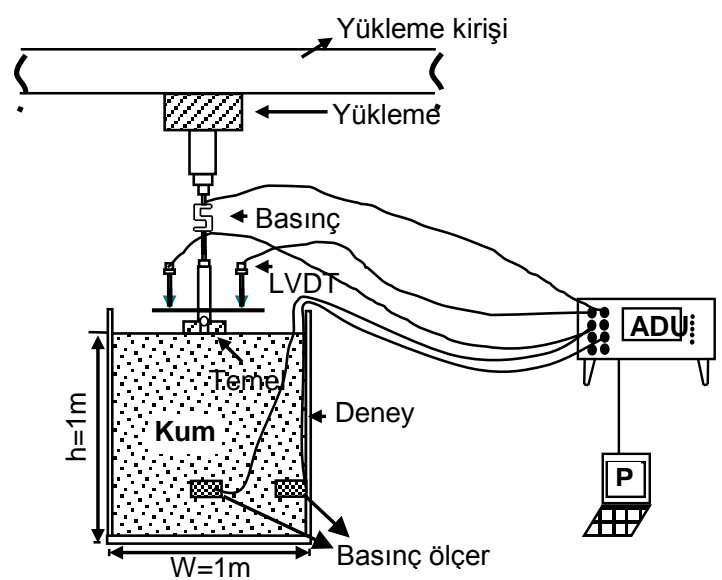

$\mathrm{W}=1 \mathrm{~m}$

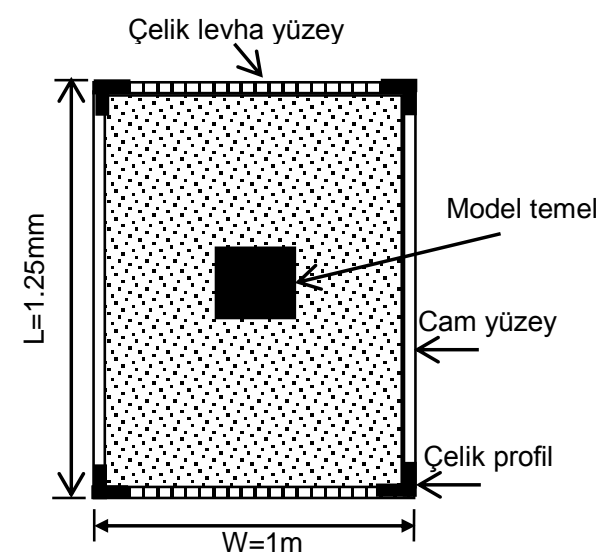

Şekil 3. Deneysel çalışmada kullanılan yükleme düzeneği 


\subsection{Deney Kumu}

Çalışmalarda, Ceyhan nehir yatağından çıkarılan kum numuneler kullanılmıştır. Kum numune, ASTM standartlarına göre elenip yıkanarak ve uygun bir alana serilerek oda sıcaklığında kurutulmuştur. Kuma ait dane çap1 dağglımı Şekil 4'te ve elek analizi, kesme kutusu, sıkılık ve piknometre deney sonuçları Çizelge 2'de verilmiştir.

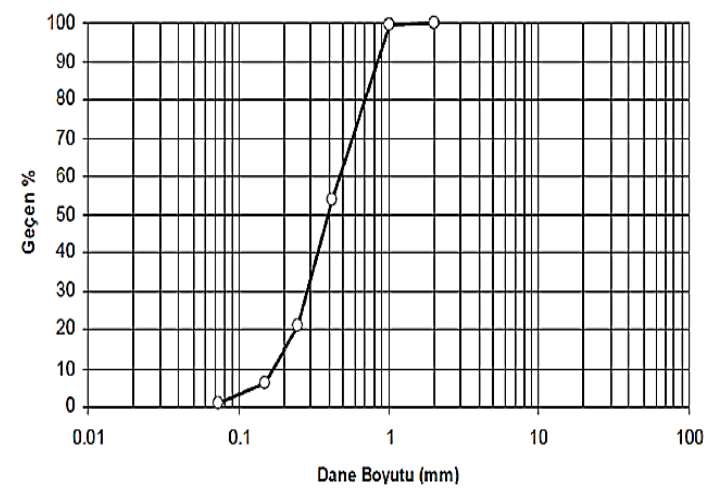

Şekil 4. Deney kumunun dane çapı dağılım eğrisi

Çizelge 2. Deney kumunun mühendislik özellikleri

\begin{tabular}{|c|c|}
\hline Özellik & Değer \\
\hline İri kum yüzdesi (\%) & $\overline{0,00}$ \\
\hline Orta kum yüzdesi (\%) & 65,00 \\
\hline İnce kum yüzdesi (\%) & 35,00 \\
\hline $\mathrm{D}_{10}(\mathrm{~mm})$ & 0,13 \\
\hline $\mathrm{D}_{30}(\mathrm{~mm})$ & 0,28 \\
\hline $\mathrm{D}_{60}(\mathrm{~mm})$ & 0,58 \\
\hline Üniformluk katsayısı, $C_{u}$ & 4,46 \\
\hline Derecelenme katsayısı, $\mathrm{C}_{\mathrm{c}}$ & 1,04 \\
\hline Özgül ağırlık & 2,72 \\
\hline $\begin{array}{l}\text { Maksimum kuru birim hacim ağırlık } \\
\left(\mathrm{kN} / \mathrm{m}^{3}\right)\end{array}$ & 17,11 \\
\hline $\begin{array}{l}\text { Minimum kuru birim hacim ağırlık } \\
\left(\mathrm{kN} / \mathrm{m}^{3}\right)\end{array}$ & 15,44 \\
\hline Kohezyon, c (kPa) & 0,00 \\
\hline İçsel sürtünme açısı, $\phi$ (derece) & 36,00 \\
\hline Zemin sinıfi (USCS) & SP \\
\hline
\end{tabular}

\subsection{Basınç Ölçer}

Uygulamalarda yüklemeler S-tipi yük ölçer (2000 kg kapasiteli) ve deplasmanlar ise LVDT deplasman ölçerler $(10 \mathrm{~cm}$ kapasiteli) ile ölçülmüştür. Zeminde meydana gelen düşey

gerilmeleri ölçmek amacıyla $2000 \mathrm{~kg}$ kapasiteli gerilme ölçer kullanılmıştır (Şekil 5).

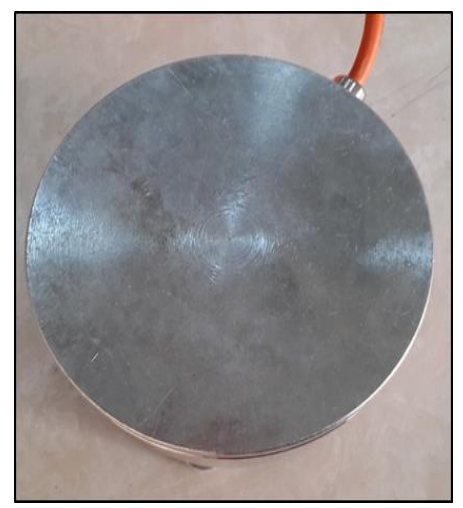

Şekil 5. Gerilme ölçer

\subsection{Deney Yöntemi}

- Deney kasasının içine yerleştirilen kumun yüzeyi su terazisi ile kontrol edildikten sonra gerilme ölçer yerleştirilmiştir.

- Daha sonra, gevşek durum için $\gamma_{\mathrm{k}}=17,11 \mathrm{kN} / \mathrm{m}^{3}$ olacak şekilde kasa içerisine beşer santim tabakalar halinde kum zemin yerleştirilmiştir.

- Düzeltilen kum zemin üzerine model temel plakası aynı şekilde teraziye alınarak yerleştirilmiştir (Şekil 6).

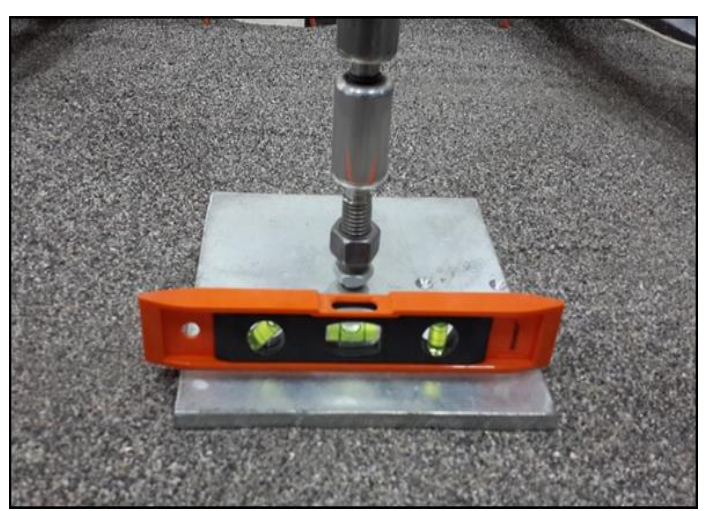

Şekil 6. Model temel plakasının yerleştirilmesi

- Deney sırasında yükleme hızı sabit tutulmuştur.

- Her yükleme kademesinde oluşan gerilmeler, 16 kanal girişli ADU (Autonomous Data Unit) veri işleme cihazından okunarak sayısal hale dönüştürülmüştür. Veri işleme ünitesinden 
bilgisayara aktarılan değerler Geotechnical Software Ds7 yazılımı kullanılarak işlenmiştir. Daha sonra da okumalar bilgisayarda Excel programiyla düzenlenerek grafik olarak sunulmuştur.

\section{BULGULAR VE TARTIŞMA}

Çalışmada, gevşek kum zemine oturan 4 farklı model temel $\left(\mathrm{K}_{1}, \mathrm{~K}_{2}, \mathrm{~K}_{3}\right.$ ve $\left.\mathrm{K}_{4}\right)$ dört farklı derinlik $(2,5 \mathrm{~B}, 5,0 \mathrm{~B}, 7,5 \mathrm{~B}$ ve $10,0 \mathrm{~B})$ için ilave düşey gerilme ve yük-oturma değerleri incelenmiştir. Her bir derinlik için yatay doğrultularda (temelin merkezi ile temelin merkezinden $3,0 \mathrm{~B}$ ve $6,0 \mathrm{~B}$ uzaklıktaki konumlarında yerleştirilen) gerilme değerleri elde edilmiştir.

\subsection{Yük-Oturma İlişkisi}

Yükleme düzeneği Şekil 7'de verilmiştir. Yükoturma eğrileri ise grafik olarak Şekil 8'de sunulmuştur.

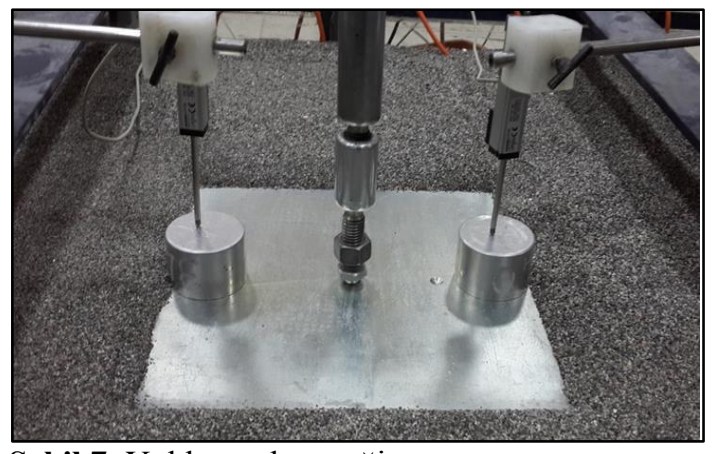

Şekil 7. Yükleme düzeneği

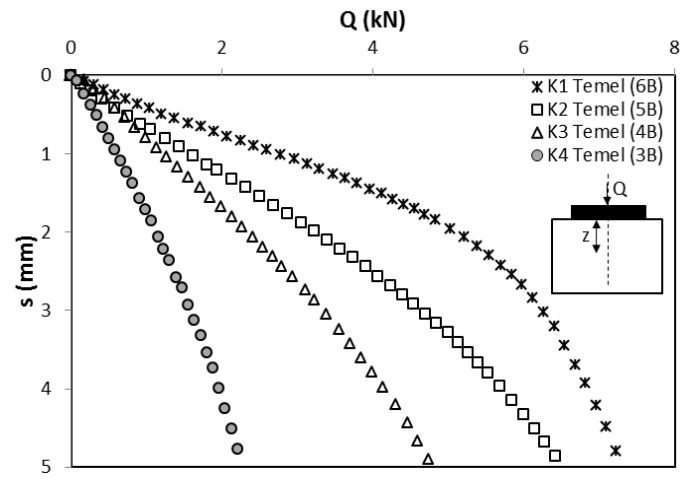

Şekil 8. Yük-oturma ilişkisi
Şekil 8'den de görüldüğü gibi, model temel boyutu arttıkça taşıma kapasitesi artmaya başlamıştır. $5 \mathrm{~mm}$ deplasman için taşıma yükü değerleri $\mathrm{K}_{1}$, $\mathrm{K}_{2}, \mathrm{~K}_{3}$ ve $\mathrm{K}_{4}(6 \mathrm{~B}$ x $6 \mathrm{~B}, 5 \mathrm{~B}$ x $5 \mathrm{~B}, 4 \mathrm{~B}$ x $4 \mathrm{~B}$ ve $3 \mathrm{~B} \times$ 3B) temelleri için yaklaşık olarak sırasıyla $7.300 \mathrm{kN}, 6,570 \mathrm{kN}, 4,800 \mathrm{kN}$ ve $2,280 \mathrm{kN}$ değerleri alarak elde edilmiştir. Temel genişliğinin 3B'den 6B'ye artmasıyla taşıma gücünde ortalama \%70 artış meydana gelmiştir.

\section{2. İlave Düşey Gerilme Artışları}

Dört farklı model temel için $20 \mathrm{kPa}$ 'lık uygulanan düşey gerilme (q) altında ölçülen gerilme değerleri 4 farklı derinlik için Şekil 9'da sunulmuştur.

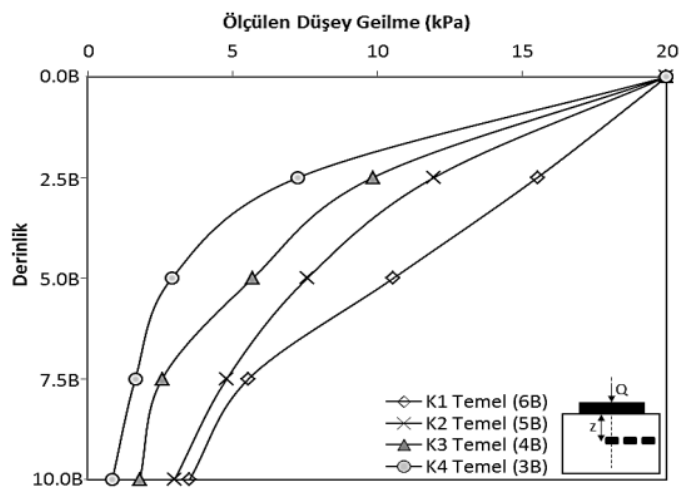

Şekil 9. Düşey gerilme dağılımı (20 kPa)

Şekil 9'da sunulan grafik incelendiğinde derinlik arttıkça tüm temeller için gerilme değerleri azaldığ1 görülmüştür. Örneğin, 5B derinlikte yüzeye göre bütün temellerde $\left(\mathrm{K}_{1}, \mathrm{~K}_{2}, \mathrm{~K}_{3}\right.$ ve $\left.\mathrm{K}_{4}\right)$ sırasıyla yaklaşı1k \%48, \%63, \%72 ve $\% 85$ mertebelerinde azalmalar görülmektedir.

\subsection{Literatür Karşılaştırması}

Uygulanan gerilmenin $20 \mathrm{kPa}$ olması halinde, test sonuçları ile Boussinesq yöntemi ile karşılaştırılmış ve elde edilen sonuçlar grafik olarak sunulmuştur (Şekil 10-13). 


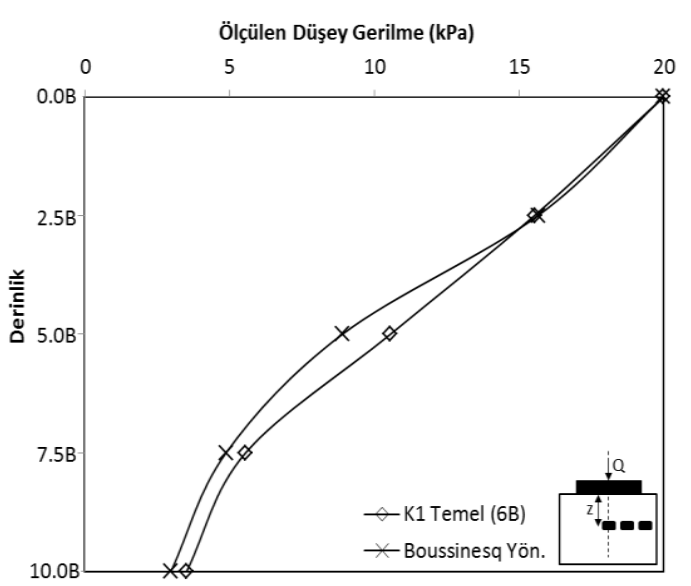

Şekil 10. $K_{1}$ temeli

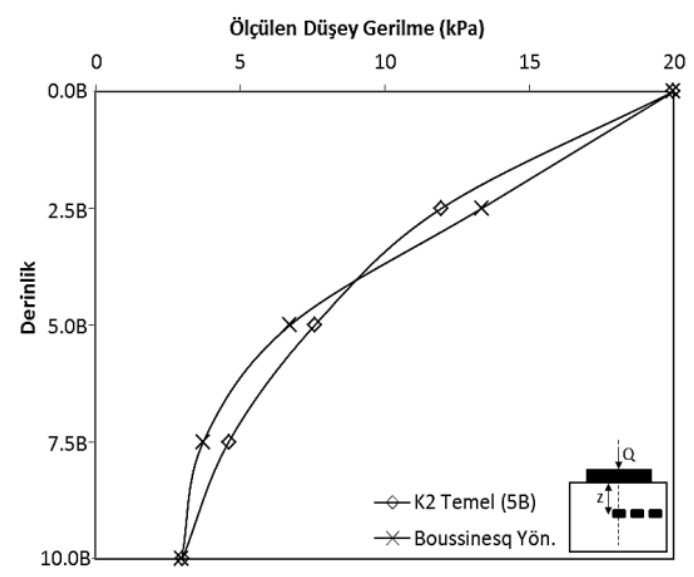

Şekil 11. $K_{2}$ temeli

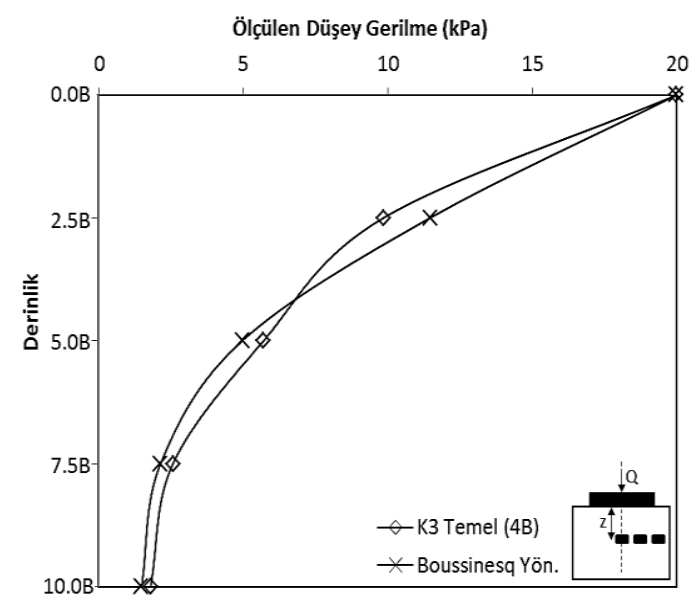

Şekil 12. $K_{3}$ temeli

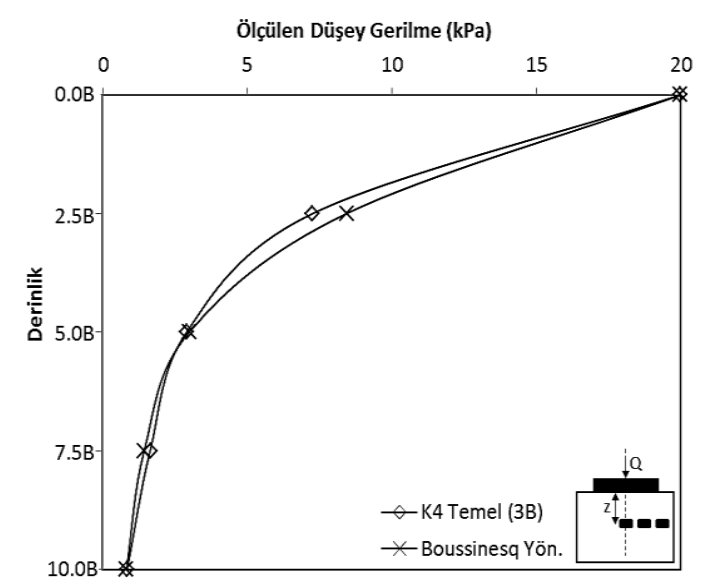

Şekil 13. $K_{4}$ temeli

Şekil 10-13 incelendiğinde, 4 farklı kare temel boyutunda da grafik sonuçlarının benzer eğilim gösterdiği ve bazı derinliklerde hemen hemen aynı sonuçlar verdiği görülmektedir. 5B derinlikte deney ve teorik sonuçları için uygulanan gerilme (q) ve ilave düşey gerilme $\left(\Delta \sigma_{z}\right)$ değerleri aşağıdaki Çizelge 3 'te verilmiştir.

Çizelge 3. 5B derinlik için literatür karşılaştırması

\begin{tabular}{|c|c|c|c|}
\hline Temel & Yöntem & $\begin{array}{c}\mathbf{q} \\
(\mathbf{k P a})\end{array}$ & $\left.\Delta \sigma_{\mathrm{z}} \mathbf{k P a}\right)$ \\
\hline \multirow{2}{*}{$\begin{array}{c}\mathrm{K}_{1} \text { temel } \\
(6 \mathrm{~B})\end{array}$} & Deney & \multirow{2}{*}{20} & 10.560 \\
\hline & Boussinesq & & 8.900 \\
\hline \multirow{2}{*}{$\begin{array}{c}\mathrm{K}_{2} \text { Temel } \\
(5 \mathrm{~B})\end{array}$} & Deney & \multirow{2}{*}{20} & 7.583 \\
\hline & Boussinesq & & 6.270 \\
\hline \multirow{2}{*}{$\begin{array}{c}\mathrm{K}_{3} \text { Temel } \\
(5 \mathrm{~B})\end{array}$} & Deney & \multirow{2}{*}{20} & 5.700 \\
\hline & Boussinesq & & 4.960 \\
\hline \multirow{2}{*}{$\begin{array}{c}\mathrm{K}_{4} \text { Temel } \\
(5 \mathrm{~B})\end{array}$} & Deney & \multirow{2}{*}{20} & 2.900 \\
\hline & Boussinesq & & 2.992 \\
\hline
\end{tabular}

\subsection{Yatay Mesafede İlave Düşey Gerilmeler}

Bu bölümde 4 farklı derinlikte $(2,5 \mathrm{~B}, 5,0 \mathrm{~B}, 7,5 \mathrm{~B}$ ve $10,0 \mathrm{~B})$ ve $20 \mathrm{kPa}$ uygulanan gerilme altında her bir temel için yatay mesafelerde oluşan gerilme değerleri araştırılmış ve elde edilen sonuçlar Şekil 14-17'de sunulmuştur. 


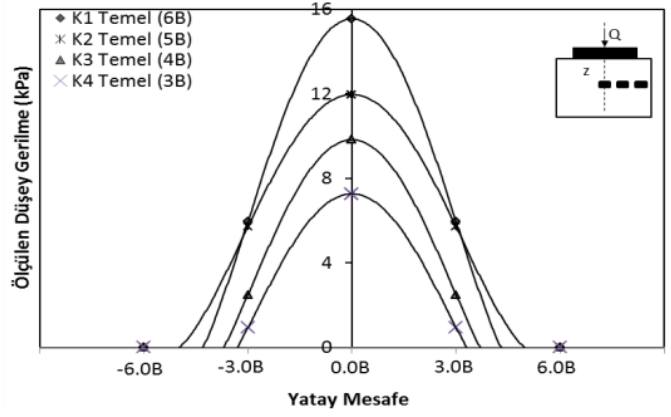

Şekil 14. 2,5B derinlik

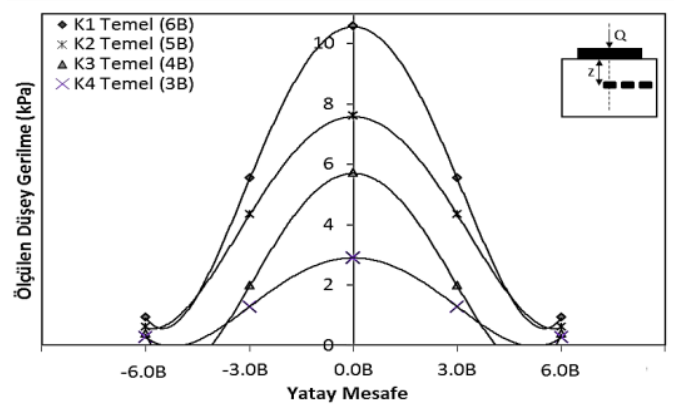

Şekil 15. 5,0B derinlik

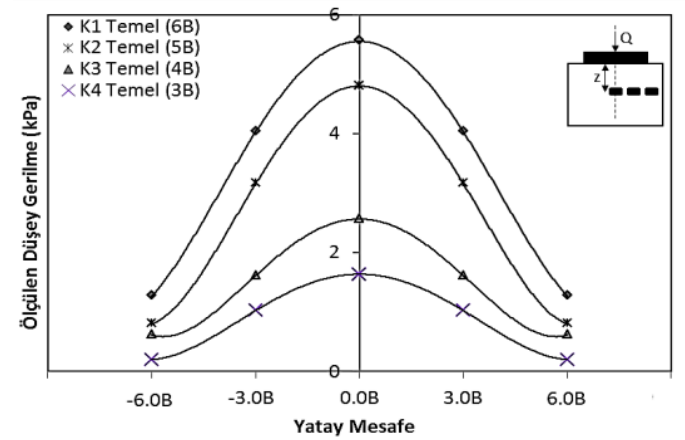

Şekil 16. 7,5B derinlik

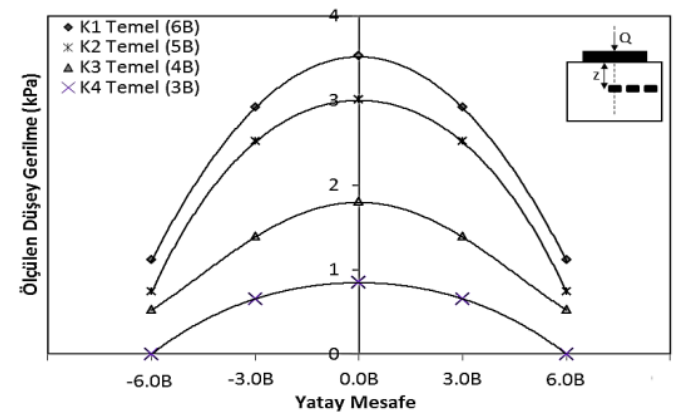

Şekil 17. 10,0B derinlik
Grafiklerden de görüleceği üzere 4 farklı temel için de en yüksek gerilme değerleri temellerin merkezi altındaki derinliklerde meydana gelmiştir. Merkezden uzaklaştıkça gerilme değerleri azalmıştır. Örneğin 10,0B derinlik için ölçülen düşey gerilme değerleri $0,0 \mathrm{~B}$ mesafede 3,0B mesafeye göre sirasiyla (K1, K2, K3 ve K4) \%69, $\% 76, \% 71$ ve \%84 oranlarında azalmıştır. Ayrıca grafikler incelendiğinde derinlik arttıkça yatay mesafedeki gerilme değerleri de azaldığ görülmektedir.

\section{SONUÇLAR}

$\mathrm{Bu}$ çalışmada, gevşek kum zemine oturan 4 farklı kare $(6 \mathrm{~B} \times 6 \mathrm{~B}, 5 \mathrm{~B} \times 5 \mathrm{~B}, 4 \mathrm{~B} \times 4 \mathrm{~B}$ ve $3 \mathrm{~B} \times 3 \mathrm{~B})$ model temel altında meydana gelen ilave düşey gerilme ve taşıma gücü davranışları deneysel ve teorik olarak araştırılmıştır. Ayrıca yük-oturma değerleri de elde edilmiştir. Elde edilen sonuçlar, literatürde mevcut teorik yöntemlerle karşılaştırılmıştır. Araştırma verilerine göre aşağıdaki sonuçlara ulaşılmıştır.

- Temel boyutunun artmasıyla birlikte taşıma gücü değeri de artmıştır.

- Temel genişliğinin iki katına çıkması ile birlikte $5 \mathrm{~mm}$ deplasman değeri için $\mathrm{K}_{1}$ temel (6B) 7,3 kN yük taşırken $\mathrm{K}_{4}$ temeli (3B) $2,28 \mathrm{kN}$ yük taşımaktadır. Yaklaşık olarak \%70'e varan taşıma gücü artışları meydana gelmiştir.

- Belirli bir uygulanan gerilme (q) altında ölçülen düşey gerilme $\left(\Delta \sigma_{z}\right)$ değerlerinde şekil etkisi olduğu görülmüştür. Ölçülen gerilmeler $\left(\Delta \sigma_{z}\right)$ ise boyutlara göre $\Delta \sigma_{K 1}>\Delta \sigma_{K 2}>\Delta \sigma_{K 3}>\Delta \sigma_{K 4}$ olarak sıralanmıştır. Örneğin 5,0B derinlikte $\Delta \sigma_{\mathrm{K} 1}=$ $10,560 \mathrm{kPa}>\Delta \sigma_{\mathrm{K} 2}=7,58 \mathrm{kPa}>\Delta \sigma_{\mathrm{K} 3}=5,70 \mathrm{kPa}$ $>\Delta \sigma_{\mathrm{K} 4}=2,90 \mathrm{kPa}$ olmaktadir.

- İlave düşey gerilme değeri 4 farklı temel türünde derinlik arttıkça azalmaktadır.

- Deneysel sonuçlar teorik sonuçlar ile benzer sonuçlar verdiği görülmüştür.

- Yatay mesafelerde en büyük gerilme değerleri temellerin merkezi altına yerleştirilen gerilme 
ölçerlerden elde edilmiştir. Merkezden uzaklaştıkça değerler azalmıştır.

\section{KAYNAKLAR}

1. Uzuner, B.A., 1998. Çözümlü Problemlerle Temel Zemin Mekaniği, Teknik Yayınevi, Ankara, 376.

2. Keskin, M.S., Laman, M., Baran, T., 2008. Kuma Oturan Kare Temeller Altında Oluşan Düşey Gerilmelerin Deneysel Tespiti ve Sayısal Analizi, İMO Teknik Dergi, 4521-4538.

3. Bağrıaçık, B., Laman, M., 2011. Donatısız ve Donat1lı Kumlu Zeminlere Oturan Dairesel Temeller Altında Gerilmelerin Değişimi, Gazi Üniversitesi Mühendislik Mimarlık Fakültesi Dergisi, Cilt 26, No 4, 787-800.

4. Yodsa-nga, P., Gasaluck, W., Punrattanasin, P., 2012. Stress Distribution in Khon Kaen Loess under Spread Footing, The Electronic Journal of Geotechnical Engineering, 17, 3753-3769.

5. Terzaghi, K., 1920. Old Earth Pressure Theories and New Test Results. Engrg, NewsRec., 85 (14), 632-637.

6. Hendron, A.J., 1963. The Behaviour of Sand in One Dimensional Compression, Ph.D. Thesis, University of Illinios, USA.

7. Sağlamer, A., 1972. Kohezyonsuz Zeminlerde Sükunetteki Toprak Basınc1 Katsayısının Zemin Parametreleri Cinsinden İfadesi, Doktora Tezi, İstanbul Teknik Üniversitesi, Fen Bilimleri Enstitüsü, İstanbul.

8. Keskin, M.S., 2004. Zeminlerde Oluşan İlave Düşey Gerilmelerin Değişik Yöntemlerle İrdelenmesi, Yüksek Lisans Tezi, Çukurova Üniversitesi, Fen Bilimleri Enstitüsü, Adana.

9. Bağrıaçık, B., 2010. Zeminlerdeki Gerilme Durumlarının Deneysel ve Teorik Olarak İncelenmesi, Yüksek Lisans Tezi, Çukurova Üniversitesi Fen Bilimleri Enstitüsü, Adana.

10. Boussinesq, J., 1885. Application des Potentiels a L'etude de L'equilbre et du Movement des Solids Elastiques, GauthierVillars, Paris.

11. Westergaard, H.M., 1938. A Problem of Elasticity Suggested by a Problem in Soil Mechanics, Soft Material Reinforced by
Numerous Strong Horizontal Sheets, Contributions to the Mechanics of Solids, S. Timoshenko $60^{\text {th }}$ Anniversary Volume, Newyork-Mac Millan.

12. Yang, K.H., Zornberg, J.G., Liu, C.N., Lin, H.D., 2012. Stress Distribution and Development within Geosynthetic-Reinforced Soil Slopes, Geosynthetics International, 19 (1), 62-78.

13. Hazzard, J.F., Yacoub T.E., Vijayakumar S., Curran, J.H., 2007. Stresses Under Footings in Multilayered Soils: A Comparative Study, Bearing Ground in the Nation's Capital, Ottowa.

14. Bhaskar, D.R.C., Shukla, S.J., Dinesh, S., 2015. A Numerical Study of Foundation Depth on Contact Stresses and Settlements for Various Sub Soils, 50 ${ }^{\text {th }}$ Indian Geotechnical Conference $17^{\text {th }}-19^{\text {th }}$ December 2015, Pune, Maharashtra, India.

15. Kayadelen, C., 2005. Investigation of Lateral Earth Pressures in $\mathrm{K}_{0}$ Condition for Unsaturated Fine Grained Soils, PhD Thesis, Cukurova University, Adana.

16. Newmark, M., 1935. Simplified Computation of Vertical Pressures in Elastic Foundations, Circular no: 24, Engng. Expt. Station, Univ. of Illınois.

17. Türedi, Y., 2015. Farklı Yükleme ve Geometri Koşullarında Gerilme Analizi, Yüksek Lisans Tezi, Mustafa Kemal Üniversitesi, Fen Bilimleri Enstitüsü, Hatay. 